\title{
Well drilling in permafrost regions: dynamics of the thawed zone
}

\author{
Lev V. Eppelbaum \& Izzy M. Kutasov ${ }^{1,2}$ \\ 'Department of Geosciences, Raymond and Beverly Sackler Faculty of Exact Sciences, Tel Aviv University, Tel Aviv, Israel; \\ ${ }^{2}$ BYG Consulting Co., Boston, MA, USA
}

\begin{abstract}
In the cold regions, warm mud is usually used to drill deep wells. This mud causes formation thawing around wells, and as a rule is an uncertain parameter. For frozen soils, ice serves as a cementing material, so the strength of frozen soils is significantly reduced at the ice-water transition. If the thawing soil cannot withstand the load of overlying layers, consolidation will take place, and the corresponding settlement can cause significant surface shifts. Therefore, for long-term drilling or oil/gas production, the radius of thawing should be estimated to predict platform stability and the integrity of the well. It is known that physical properties of formations are drastically changed at the thawingfreezing transition. When interpreting geophysical logs, it is therefore important to know the radius of thawing and its dynamics during drilling and shut-in periods. We have shown earlier that for a cylindrical system the position of the phase interface in the Stefan problem can be approximated through two functions: one function determines the position of the melting-temperature isotherm in the problem without phase transitions, and the second function does not depend on time. For the drilling period, we will use this approach to estimate the radius of thawing. For the shut-in period, we will utilize an empirical equation based on the results of numerical modelling.
\end{abstract}

\section{Keywords}

Radius of thawing; freezeback period; permafrost temperature; Stefan problem

\section{Correspondence}

Lev V. Eppelbaum, Department of Geosciences, Raymond and Beverly Sackler Faculty of Exact Sciences, Tel Aviv University, Ramat Aviv 6997801, Tel Aviv, Israel. E-mail: levap@post.tau.ac.il

\section{Introduction}

The problem of phase change (Stefan problem) around a cylindrical source occurs in many engineering designs: oil/gas production/injection wells in permafrost areas, underground pipelines, steam production boreholes, melting of metals and storage of nuclear waste. In the cylindrical coordinates, an exact solution of the Stefan problem in the infinite domain exists only for two cases: subcooled liquid, which freezes while the solidified region remains at the fusion temperature; and a line source, which extracts energy at some constant rate per unit length (Carslaw \& Jaeger 1959). Heat balance integral solutions were applied to the problem of finite superheat, when the initial temperature of the medium is lower than the fusion temperature (Tien \& Churchill 1965; Sparrow et al. 1978; Lunardini 1988). Different numerical methods were used to solve the heat valance integral equations, but the results were essentially the same (Lunardini 1988). A coordinate transformation method reduced the problem with a variable phase change, such as a cylinder, to one with a constant phase change area (Lin 1971). An interesting effective thermal diffusivity concept was introduced (Churchill \& Gupta 1977). It was assumed that the actual thermal diffusivity could be replaced by the effective thermal diffusivity, which includes the latent heat. The accuracy of these two methods is limited to certain ranges of dimensionless parameters (Lunardini 1988).

When wells are drilled through permafrost, the natural temperature field of the formations in the vicinity of the borehole is disturbed and the frozen rocks thaw for some distance from the borehole axis (e.g., Romanovsky et al. 2007; Eppelbaum et al. 2014). Making geothermal measurements to determine the static temperature of the formation and the permafrost thickness must be postponed for some period after completion of the drilling. This is the so-called restoration time. A lengthy restoration period of up to 10 years or more is required to determine the temperature and thickness of permafrost with sufficient accuracy (Lachenbruch \& Brewer 1959; Melnikov et al. 1973; Shiu \& Beggs 1980; Judge et al. 1981; Taylor et al. 1982; Clow 2014; Eppelbaum et al. 2014). The duration of the refreezing of the layer thawed during drilling is very dependent on the natural temperature of the formation; therefore, the rocks at the bottom 
of the permafrost refreeze very slowly (e.g., Dobinski 2011). The position of the interface of the thawing-freezing transition can be determined with resistivity and sonic logs. For example, the transition from higher resistivity and velocity readings to lower values can be considered as the position of the thawing radius. In our recent paper, we suggested a method to estimate how long it takes for formations thawed by drilling to refreeze (Kutasov \& Eppelbaum 2017a, b). The method requires just three temperature logs taken after the freezeback is completed. Earlier we conducted numerical modelling and found that the dimensionless time of refreezing can be expressed as a function of two dimensionless parameters: the dimensionless radius of thawing and the dimensionless latent heat density (Kutasov 1999, 2006). Kutasov et al. (1977) proposed an effective approach for solving the problem of phase change (Stefan problem) around a cylindrical source of heat. It was shown that a known solution for a planar system can be utilized to obtain an approximate solution of the Stefan problem for a cylindrical source of heat with a constant temperature. Later (Kutasov 1998), we used an adjusted heating time concept (Kutasov 1987, 1999) to determine the position of a thawing temperature isotherm in the problem without the ice-water transition. The results of numerical solutions presented in Taylor (1978) were used to verify the results of our calculations.

It was shown that for a cylindrical system the position of the phase interface in the Stefan problem can be approximated through two functions. One function $\left(r_{m}\right)$ determines the position of the melting-temperature isotherm in the problem without phase transitions, and the second function $\Psi$ does not depend on the time (Kutasov et al. 1977; Kutasov 1998, 2006; Eppelbaum et al. 2014). Recently, Wang et al. (2017) reported an interesting study in which they developed a coupled thermal model of the wellbore-permafrost system. It considered the latent heat of fusion, water migration and the change in thermal parameters. In this study, work done by Ramey (1962) and the temperature prediction model for incompressible fluids developed by Wu \& Pruess (1990) and Hasan and Kabir (1994) were used to describe heat transfer in the borehole-formation system. Numerical solutions of moisture transfer problems for frozen soil were based on the equations given by Harlan (1973). For numerical simulations, Wang et al. (2017) selected a simulation well: well depth is $3100 \mathrm{~m}$ and thickness of permafrost is $750 \mathrm{~m}$. The suggested coupled thermal model of the wellbore in permafrost regions allowed for the estimation of the volume of thawed permafrost (and the corresponding radius of thawing) and radial temperature of formations. It was also shown that the use of low thermal conductivity cements significantly reduces the volume of thawed permafrost. The most important result of the study by
Table 1 Comparison of values of position of $0^{\circ} \mathrm{C}$ isotherm: $r_{D m}$ (Eqn. 6), $R$ (numerical modelling; Taylor 1978).

\begin{tabular}{|c|c|c|c|c|c|c|c|c|}
\hline \multirow[t]{2}{*}{$r_{D m}$} & \multicolumn{2}{|c|}{$t_{D}=100$} & \multicolumn{2}{|c|}{$t_{D}=300$} & \multicolumn{2}{|c|}{$t_{D}=500$} & \multicolumn{2}{|c|}{$t_{D}=1000$} \\
\hline & $\theta$ & $R$ & $\theta$ & $R$ & $\theta$ & $R$ & $\theta$ & $R$ \\
\hline 2 & 0.761 & 1.968 & 0.797 & 1.977 & 0.810 & 1.983 & 0.826 & 1.984 \\
\hline 3 & 0.621 & 2.934 & 0.678 & 2.950 & 0.700 & 2.949 & 0.725 & 2.955 \\
\hline 4 & 0.523 & 3.893 & 0.594 & 3.918 & 0.621 & 3.924 & 0.653 & 3.926 \\
\hline 5 & 0.447 & 4.864 & 0.529 & 4.887 & 0.560 & 4.897 & 0.597 & 4.899 \\
\hline 6 & 0.386 & 5.836 & 0.476 & 5.857 & 0.511 & 5.854 & 0.551 & 5.878 \\
\hline 7 & 0.335 & 6.820 & 0.432 & 6.816 & 0.469 & 6.826 & 0.513 & 6.835 \\
\hline 8 & 0.292 & 7.805 & 0.393 & 7.806 & 0.433 & 7.794 & 0.479 & 7.826 \\
\hline 9 & 0.255 & 8.797 & 0.360 & 8.766 & 0.401 & 8.774 & 0.450 & 8.787 \\
\hline 10 & 0.223 & 9.793 & 0.330 & 9.753 & 0.373 & 9.741 & 0.424 & 9.753 \\
\hline 11 & 0.195 & 10.797 & 0.303 & 10.749 & 0.347 & 10.741 & 0.400 & 10.742 \\
\hline 12 & 0.170 & 11.826 & 0.279 & 11.735 & 0.324 & 11.721 & 0.379 & 11.694 \\
\hline 13 & - & - & 0.257 & 12.735 & 0.303 & 12.703 & 0.359 & 12.684 \\
\hline 14 & - & - & 0.238 & 13.683 & 0.284 & 13.673 & 0.341 & 13.652 \\
\hline 15 & - & - & 0.219 & 14.722 & 0.266 & 14.672 & 0.324 & 14.640 \\
\hline 16 & - & - & 0.202 & 15.739 & 0.249 & 15.695 & 0.308 & 15.64 \\
\hline
\end{tabular}

Wang et al. (2017) is the following: very low rate of water migration (only $4.72 \times 10^{-5} \mathrm{~m}^{3} / \mathrm{s}$ ) (see the parameters for a simulated well, Table 1 in Wang et al. 2017). As a result, the heat transferred with the water migration is negligible compared with the heat caused by heat conduction. The simulation results (radius of thawing) can be validated against data obtained by geophysical logging (see also end of the "Time of the complete freezeback" section) and by temperature logs taken during shut-in (the degree of thermal disturbance caused by drilling).

The objective of this study is to estimate the dynamics of the unfrozen zone (radius of thawing during drilling and shut-in periods). To demonstrate the applicability of the suggested equations in estimating the formation temperature, the radius of thawing and the time of complete freezeback in a field case are presented.

\section{The drilling period}

The results of field and analytical investigations have shown that in many cases the effective temperature $\left(T_{w}\right)$ of the circulating fluid (mud) at a given depth can be assumed constant during drilling or production (Lachenbruch \& Brewer 1959; Jaeger 1961; Edwardson et al. 1962; Ramey 1962; Kutasov et al. 1966; Raymond 1969). Here we should note that even for a continuous mud circulation process the wellbore temperature is dependent on the current well depth and other factors. The term "effective fluid temperature" is used to describe the temperature disturbance of formations while drilling. We should note that the effective temperature $T_{w}$ takes into 
account the changes in heat transfer during all period of mud circulation on the given depth. The good agreement between calculated values of transient (shut-in) temperatures and the results of temperature surveys in numerous wellbores in permafrost regions confirms this assumption (Kutasov 1999; Kutasov \& Eppelbaum 2003). Because of its low permeability, water migration is usually neglected in permafrost studies. Recent numerical modelling was used to confirm this assumption (Wang et al. 2017).

Lachenbruch \& Brewer (1959) have shown that the wellbore shut-in temperature mainly depends on the amount of thermal energy transferred to (or from) formations. Therefore, for every depth a value of $T_{w}$ can be estimated from shut-in temperature logs. Drawing from Kutasov's earlier work (1977, 1998, 2006), we can write that

$$
\left\{\begin{array}{l}
h_{0}=r_{w}+\Psi\left(r_{m}-r_{w}\right), H_{0}=1+\Psi\left(R_{m}-1\right) \\
H_{0}=\frac{h_{0}}{r_{w}}, R_{m}=\frac{r_{m}}{r_{w}}
\end{array}\right\}
$$

where $r_{w}$ is the radius of the well and $h_{0}$ is the radius of thawing. The function $r_{m}$ determines the position of the melting-temperature isotherm in the problem with phase transition. The function $\Psi$ shows to what extent the melting process affects the position of the melting-temperature isotherm and does not depend on time. From physical considerations, it follows that $0<\Psi<1$. The function $r_{m}$ is known, but is expressed through a complex integral. By introducing an adjusted dimensionless heating time $\left(t_{D}^{*}\right)$, we have found (Kutasov 1987) that the exponential integral (a tabulated function) can be used to approximate the function $T_{D}=T\left(r_{D^{\prime}}, t_{D}\right)$ :

$$
T_{D}=\frac{T_{m}-T_{f}}{T_{w}-T_{f}}=\frac{E i\left(-r_{D}^{2} / 4 t_{D}^{*}\right)}{E i\left(-1 / 4 t_{D}^{*}\right)}
$$

where

$$
\begin{gathered}
t_{D}^{*}=G t_{D}, t_{D}=\frac{a_{1} t}{r_{w}^{2}}, r_{D}=\frac{r}{r_{w}}, \\
\left\{\begin{array}{l}
G=\frac{t_{c}^{*}}{t}=\frac{t_{D}^{*}}{t_{D}}=1+\frac{1}{1+A F}, t_{D} \leq 10, \\
F=\left[\ln \left(1+t_{D}\right)\right]^{n}, n=2 / 3, A=7 / 8 .
\end{array}\right\}, \\
G=\frac{t^{*}}{t}=\frac{t_{D}^{*}}{t_{D}}=\frac{\ln t_{D}-\exp \left(-0.236 \sqrt{t_{D}}\right)}{\ln t_{D}-1}, t_{D}>10,
\end{gathered}
$$

where $r$ is the cylindrical coordinate, $r_{D}$ is the dimensionless radial distance, $\operatorname{Ei}(x)$ is the exponential integral, $T_{w}$ is the temperature at the wall of the borehole, $T_{m}$ is the temperature of melting, $T_{f}$ is the initial temperature, $T(r, t)$ is the radial temperature, $T\left(r_{D^{\prime}} t_{D}\right)$ is the dimensionless radial temperature, $t_{D}$ is the dimensionless time and $a_{1}$ is the thermal diffusivity of the frozen formation.

The correlation coefficient $G\left(t_{D}\right)$ varies in the narrow limits: $G(0)=2$ and $G(\infty)=1$. From Eqn. 2 (assuming that $T=T_{m}$ ) we can determine the position of the melting-temperature isotherm. In our case, the melting temperature (for pure ice) is $0^{\circ} \mathrm{C}$, and the following equation can be used to determine $r_{m}$

$$
\theta=\frac{\theta_{0}}{1+\theta_{0}}=\frac{E i\left(-r_{D m}^{2} / 4 t_{D}^{*}\right)}{E i\left(-1 / 4 t_{D}^{*}\right)}, \theta_{0}=-\frac{T_{f}}{T_{w}}, r_{D m}=\frac{r_{m}}{r_{w}}
$$

As can be seen from Table 1, Eqn. 6 approximates the position of $0^{\circ} \mathrm{C}$ isotherm with good accuracy.

Analysis of physical characteristics indicates that at the very small times the solutions for cylindrical systems approach those for plane systems. For this reason, we assumed that the function $\Psi$ can be determined from the known solution for the plane Stefan problem (Carslaw \& Jaeger 1959). In a plane system, the position of the solid-melted interface is

$$
\begin{gathered}
X=2 \lambda \sqrt{a_{2} t} \\
\frac{\exp \left(-\lambda_{2}\right)}{\Phi(\lambda)}-\frac{\lambda_{1} \sqrt{a_{2}}\left(T_{m}-T_{f}\right) \exp \left(\frac{-\lambda_{2} a_{2}}{a_{1}}\right)}{\lambda_{2} \sqrt{a_{2}}\left(T_{s}-T_{m}\right) \Phi *\left(\lambda \sqrt{a_{2} / a_{1}}\right)}=\frac{\sqrt{\pi} \lambda L w}{c_{2} \rho\left(T_{s}-T_{m}\right)}
\end{gathered}
$$

Here, subscripts ${ }_{1}$ and ${ }_{2}$ correspond to the frozen and thawed zones, respectively, $\lambda$ is the thermal conductivity, $c$ is the specific heat, $T_{s}$ is the surface temperature, $\rho$ is the density, $L$ is the latent heat per unit of mass, $w$ is the ice mass content per unit of volume, $\Phi$ is the probability integral and $\Phi *=1-\Phi$.

Introducing the dimensionless parameters, we obtain

$$
\begin{gathered}
\frac{\exp \left(-\lambda_{2}\right)}{\Phi(\lambda)}-\frac{I_{k a} \theta \exp \left(-\lambda_{2} I_{a}\right)}{\Phi *\left(\lambda \sqrt{I_{a}}\right)}=\sqrt{\pi} I_{f} \lambda, \\
I_{k a}=\frac{\lambda_{1} \sqrt{a_{2}}}{\lambda_{2} \sqrt{a_{1}}}, I_{a}=\frac{a_{2}}{a_{1}}, \\
\theta=\frac{T_{m}-T_{f}}{T_{s}-T_{m}}, I_{f}=\frac{L w}{c_{2} \rho\left(T_{s}-T_{m}\right)} .
\end{gathered}
$$

As we can see (Eqn. 7), the depth of thawing $X$ is a product of two functions and the function $\lambda$ does not 
depend on time. The changes of thermal properties are due to thawing, and therefore, by using our assumption, we obtain from Eqn. 8 that

$$
\Psi=\frac{\lambda(w)}{\lambda\left(\lambda_{1}=\lambda_{2}, a_{1}=a_{2}, w=0\right)} .
$$

The results of a numerical solution (Taylor 1978) and results of calculations (after Eqns. 1-10) were compared (Kutasov 2006). It was found that both approximate solutions are in satisfactory agreement.

\section{Shut-in period}

After the cessation of the drilling process, the radius of thawing and the radius of thermal influence will increase for a definite period of time $\Delta t_{0}$ at the expense of the heat accumulated in the thawed zone. Correspondingly, the increase of the radius of thawing will be $\Delta h_{0}$. We suggested an empirical relationship to estimate the parameter $\Delta t_{0}$ (Kutasov 1999: 181). Hydrodynamical modelling (Kutasov 1999) has shown that the maximum value of the thawing radius can be given by

$$
h_{\max }=h\left(t_{c}+\Delta t_{0}\right) \approx\left(1+0.43 \frac{\Delta t_{0}}{t_{c}}\right) h\left(t_{c}\right),
$$

where $t_{c}$ is the drilling mud circulation time at a given depth.

As an example, the results of one iteration of the hydrodynamic modelling are presented in Fig. 1. The input parameters are the time of heating disturbance

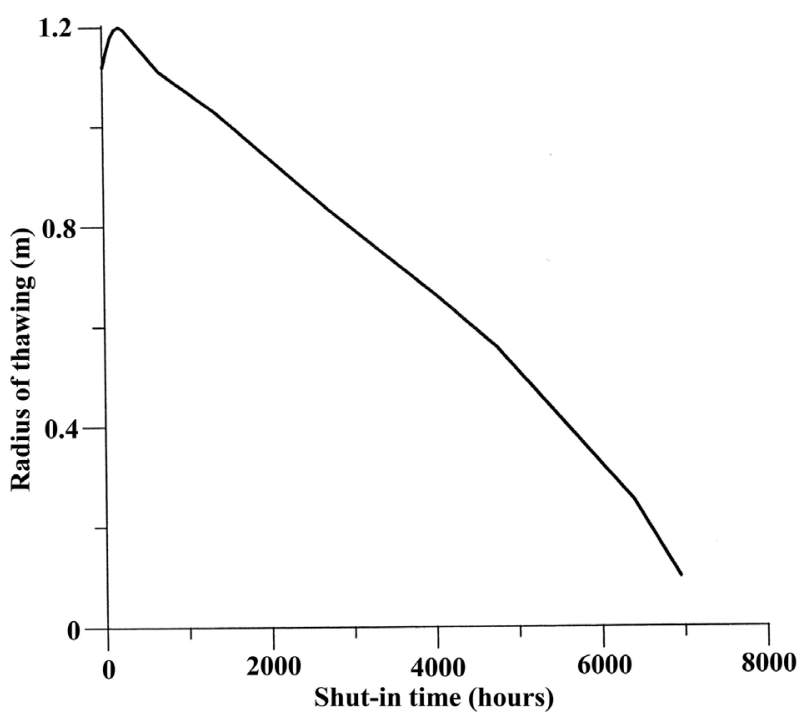

Fig. 1 Dynamics of the thawed zone. $t_{c}=2200 \mathrm{hr}$, the temperature of drilling mud is $T_{m}=8^{\circ} \mathrm{C}$, the temperature of the formation is $T_{f}=-2^{\circ} \mathrm{C}$, the well radius is $r_{w}=0.1 \mathrm{~m}$, thermal diffusivity and thermal conductivity of the thawed formation is $a_{t}=0.0030 \mathrm{~m}^{2} / \mathrm{h}$ and $\lambda_{t}=2.0 \mathrm{kcal} /\left(\mathrm{h} \cdot \mathrm{m} \cdot{ }^{\circ} \mathrm{C}\right)$ and the thermal conductivity of the permafrost (frozen area) is $\lambda_{f}=2.5 \mathrm{kcal} /\left(\mathrm{h} \cdot \mathrm{m} \cdot{ }^{\circ} \mathrm{C}\right.$ ).

We obtained that $h\left(t_{c}\right)=1.12 \mathrm{~m}, \Delta t_{0}=113$ hours and

$$
h_{\max }=1.12\left(1+0.43 \frac{113}{2200}\right)=1.14(\mathrm{~m}) \text {. }
$$

Below we will neglect the difference between $h_{c}$ and $h_{\text {max }}$. Refreezing of the thawed zone starts at the moment of time $t=t_{0}$ and ends at $t=t_{\text {ep }}$ (Fig. 2).

We should note that only a part of the formation's pore water changes to ice at $0^{\circ} \mathrm{C}$. With further lowering of the temperature, phase transition of the water continues, but at steadily decreasing rates. The amount of unfrozen water is practically independent of the total moisture content for a given soil (Tsytovich 1975).

\section{Time of the complete freezeback}

It was assumed that the heat flow from the thawed zone to the thawed zone-frozen zone interface can be neglected. The results of hydrodynamical modelling have shown that this is a valid assumption (Kutasov 1999). In this case, the Stefan equation-energy conservation condition at phase change interface $(r=h)$ is

$$
\left.\lambda_{f} \frac{d T_{f}(r, t)}{d r}\right|_{r=h}=L w \frac{d h}{d t} .
$$

Assuming the semi-steady temperature distribution in frozen zone (a conventional assumption), we obtain

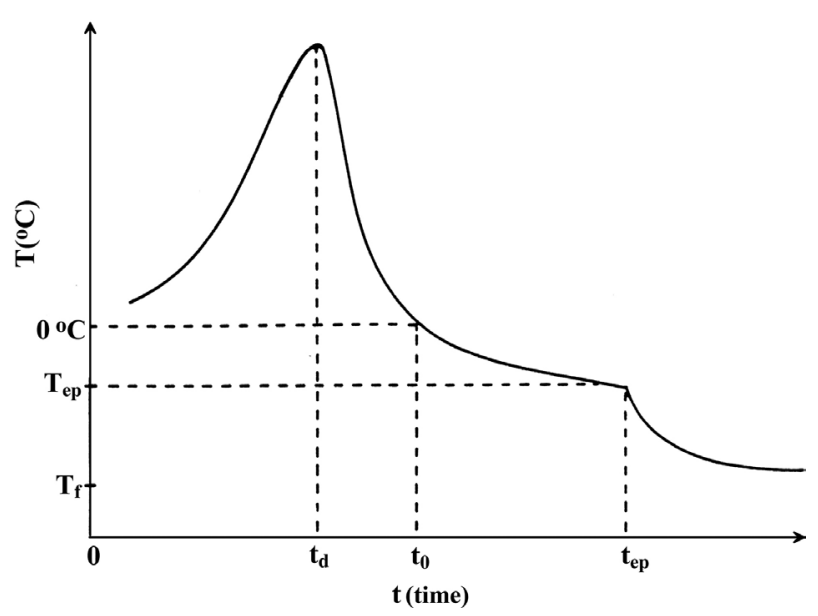

Fig. 2 Downhole temperature versus time for a given depth shown as a schematic curve. 


$$
T_{f}(r, t)=T_{f} \frac{\ln r / h}{\ln r_{i f} / h}
$$

where $r_{i f}$ is the radius of thermal influence during the freezeback period. The ratio $D_{f}=r_{i f} / h$ was determined from a numerical solution. A computer programme was used to obtain a numerical solution of a system of differential equations of heat conductivity for frozen and thawed zones and the Stefan equation (Kutasov 1999, 2006). It was found that

$$
\begin{gathered}
D_{f}=2.00+0.25 \operatorname{In}\left(I_{f}+1\right), 1.5<I_{f} \leq 400, \\
1.25<H<23.4 \\
I_{f}=-\frac{L \phi \rho_{w} a_{f}}{T_{f} \lambda_{f}}=-\frac{L \phi \rho_{w} a_{f}}{T_{f} \rho a_{f} \mathcal{c}_{f}}=-\frac{L \phi \rho_{w}}{T_{f} \rho_{f} \mathcal{c}_{f}}, H_{\max }=\frac{h_{\max }}{r_{w}},
\end{gathered}
$$

where $I_{f}$ is the dimensionless latent heat density, $L$ is the latent heat per unit of mass, $c_{f}$ is the specific heat of the formation, $\phi$ is porosity, $\rho_{w}$ is the water density, $\rho_{f}$ is the formation density, $r_{w}$ is the well radius, and $\lambda_{f}$ and $a_{f}$ are the thermal conductivity and diffusivity of frozen formations, respectively.

From Eqns. 14-16 and the condition $h\left(t_{0}\right)=h_{\max ^{\prime}}$ we obtained (Kutasov 1999, 2006)

$$
t_{f D}=\frac{D_{f} I_{f}}{2}\left(H_{\max }^{2}-H^{2}\right), t_{f D}=\frac{a_{f}\left(t-t_{0}\right)}{r_{w}^{2}},
$$

where $H$ is the dimensionless radius of the thawing during shut-in.

From Eqn. 18 at $h=r_{w^{\prime}}$ we obtain the relationship for the duration of complete freezeback $t_{c f}=t_{e p}-t_{0}$ (Fig. 2).

$$
\left\{t_{c f D}=\frac{D_{f} I_{f}}{2}\left(H_{\max }^{2}-1\right), t_{c f D}=\frac{a_{f} t_{c f}}{r_{w}^{2}}, t_{e p D}=\frac{a_{f} t_{e p}}{r_{w}^{2}}=\frac{D_{f} I_{f}}{2}\left(H^{2}-1\right)\right\},
$$

where $t_{e p D}$ is the dimensionless time of refreezing.

It is known that the electric resistivity of frozen sediments is affected by the freezing-thawing transition to a greater extent than the seismic velocities. Seismic velocities may increase by $2-10$ times in transition to a frozen state, whereas the electrical resistivity may increase by 30 to 300 times in the same temperature interval (Hnatiuk \& Randall 1977; Dobinski 2011). The dynamics of the thawed zone (the radius of thawing, Eqn. 18) while refreezing can, therefore, be monitored by geophysical methods (electric resistivity and seismic logs).

\section{Method testing and discussion}

\section{Field example, Well Put River N-1, Alaska}

The input data and location of this well are presented in Table 2. This is a unique wellbore. Indeed, the first temperature log was taken after five days of shut-in and the last after three years of shut-in (Table 3). As we can see, the refreezing time increases with sufficiently high accuracy with the formation temperature increasing (Table 4). Figure 3 shows the results of calculations after Eqn. 1. It is clear that Eqn. 1 approximates the observed shut-in temperatures with sufficiently high accuracy.

The medium is a permafrost formation (sandstone). Only heat transfer by radial conduction is considered. The following parameters are introduced: the radius of the wellbore is 0.255 , the thermal conductivity of frozen and unfrozen formations are $\lambda_{f}=4.40$ and $\lambda_{u n}$ $=3.84 \mathrm{Wm}^{-1} \mathrm{~K}^{-1}$, specific heat $c_{f}=950$ and $c_{\text {un }}=1138$ $\mathrm{Jkg}^{-1} \mathrm{~K}^{-1}$, the density of sandstone is $\rho_{\mathrm{f}}=2483 \mathrm{~kg} \mathrm{~m}^{-3}$, the density of water/ice is $\rho_{w}=1000 \mathrm{~kg} \mathrm{~m}^{-3}$, porosity is $\phi=0.09$, and latent heat $L=334960 \mathrm{~J} \mathrm{~kg}^{-1}$ for water/ ice. The latent heat density of the medium is $\chi=L \rho_{w} \phi=$ $334960 \times 1000 \times 0.09=30 \times 10^{6} \mathrm{Jm}^{-3}$. The duration of the source disturbance is $t_{c}$. The phase change is assumed to be at $0^{\circ} \mathrm{C}$. The temperature of drilling mud is assumed to be $8^{\circ} \mathrm{C}$.

\section{Estimation of the formation temperature}

Recently, we suggested a new approach in predicting the undisturbed formations temperatures from shut-in temperature logs in deep wells (Kutasov \& Eppelbaum 2018). The main features of the suggested method are the following: the refreezing of the thawed formations (around the wellbore) is completed; the temperature logs are taken after refreezing and the starting point in the well thermal recovery is moved from the end of well completion to the moment of time when the first shut-in temperature log

Table 2 Input data and location of the example well (USGS 1998).

\begin{tabular}{lc}
\hline Site code & PBF \\
\hline Site name & Put River, N-1, Alaska \\
Latitude & $70^{\circ} 19^{\prime} 07^{\prime \prime} \mathrm{N}$ \\
Longitude & $148^{\circ} 54^{\prime} 35^{\prime \prime} \mathrm{W}$ \\
Surface elevation (m) & 8 \\
Casing diameter (cm) & 51 \\
Hole depth (m) & 763 \\
Date of drill start & $02 / 09 / 70$ \\
Drilling time (days) & 44 \\
Number of logs & 9 \\
Shut-in time (days) & $5-1071$ \\
\hline
\end{tabular}


Table 3 Observed shut-in temperatures (in ${ }^{\circ} \mathrm{C}$ ) in well Put River N-1, Alaska.

\begin{tabular}{|c|c|c|c|c|c|c|c|c|c|}
\hline \multirow[t]{2}{*}{$z(m)$} & \multicolumn{9}{|c|}{ Shut-in time (days) } \\
\hline & 5 & 22 & 34 & 48 & 66 & 91 & 117 & 163 & 1071 \\
\hline 30.48 & -0.400 & -2.686 & -4.793 & -6.252 & -7.040 & -7.602 & -7.970 & -8.716 & -9.167 \\
\hline 45.72 & -0.300 & -2.093 & -4.507 & -6.012 & -6.910 & -7.511 & -7.900 & -8.428 & -9.052 \\
\hline 60.96 & -0.250 & -2.941 & -4.911 & -6.148 & -6.950 & -7.497 & -7.860 & -8.263 & -8.957 \\
\hline 91.44 & -0.300 & -1.633 & -4.101 & -5.646 & -6.590 & -7.227 & -7.620 & -7.965 & -8.771 \\
\hline 121.92 & -0.210 & -0.882 & -2.565 & -4.781 & -6.060 & - & -7.250 & -7.624 & -8.520 \\
\hline 152.40 & -0.030 & -0.976 & -1.852 & -3.173 & -4.760 & -5.880 & -6.510 & -7.026 & -8.124 \\
\hline 182.88 & 0.020 & -0.757 & -1.217 & -2.506 & - & - & -6.140 & -6.600 & -7.619 \\
\hline 213.36 & 0.200 & -0.490 & -0.805 & -1.528 & - & -5.049 & -5.680 & -6.111 & -7.144 \\
\hline 243.84 & 0.380 & -0.433 & -0.608 & -0.950 & -2.660 & - & - & -5.521 & -6.602 \\
\hline 274.32 & 0.640 & -0.418 & -0.555 & -0.823 & - & -3.186 & - & -4.822 & -6.029 \\
\hline 304.80 & 0.740 & -0.379 & -0.506 & -0.682 & -1.150 & - & -3.610 & -4.325 & -5.462 \\
\hline 335.28 & 0.910 & -0.325 & -0.451 & -0.577 & - & -1.720 & -2.840 & -3.705 & -4.935 \\
\hline 365.76 & 1.040 & -0.322 & -0.452 & -0.579 & -0.800 & - & -2.290 & -3.258 & -4.454 \\
\hline 396.24 & 1.230 & -0.354 & -0.505 & -0.644 & -0.860 & -1.248 & -1.880 & -2.677 & -4.039 \\
\hline 426.72 & 1.220 & -0.280 & -0.415 & -0.517 & -0.630 & - & -1.130 & -1.796 & -3.453 \\
\hline
\end{tabular}

Table 4 Results of calculations $B$ and $T_{f}$.

\begin{tabular}{lccccccc}
\hline$z(\mathrm{~m})$ & \multicolumn{1}{c}{$t_{0}$} & \multicolumn{1}{c}{$t_{2}$} & \multicolumn{1}{c}{$t_{3}$} & $T_{2}\left({ }^{\circ} \mathrm{C}\right)$ & $T_{3}\left({ }^{\circ} \mathrm{C}\right)$ & $T_{f}\left({ }^{\circ} \mathrm{C}\right)$ & $B\left({ }^{\circ} \mathrm{C}\right)$ \\
\hline 30.48 & 22 & 48 & 66 & -6.252 & -7.040 & -9.101 & 2.289 \\
45.72 & 22 & 48 & 66 & -6.012 & -6.910 & -9.248 & 2.621 \\
60.96 & 22 & 48 & 66 & -6.148 & -6.950 & -9.029 & 2.352 \\
91.44 & 22 & 48 & 66 & -5.646 & -6.590 & -9.016 & 2.797 \\
121.92 & 22 & 48 & 66 & -4.781 & -6.060 & -9.316 & 3.830 \\
152.40 & 22 & 48 & 66 & -3.173 & -4.760 & -8.763 & 4.804 \\
182.88 & 48 & 117 & 163 & -6.140 & -6.600 & -7.609 & 1.885 \\
213.36 & 48 & 91 & 163 & -5.049 & -6.111 & -7.182 & 2.034 \\
243.84 & 66 & 163 & 1071 & -5.521 & -6.602 & -6.767 & 1.812 \\
274.32 & 91 & 163 & 1071 & -4.822 & -6.029 & -6.190 & 1.401 \\
304.80 & 117 & 163 & 1071 & -4.325 & -5.462 & -5.587 & 0.892 \\
335.28 & 117 & 163 & 1071 & -3.705 & -4.935 & -5.069 & 0.970 \\
365.76 & 117 & 163 & 1071 & -3.258 & -4.454 & -4.584 & 0.949 \\
396.24 & 117 & 163 & 1071 & -2.677 & -4.039 & -4.186 & 1.088 \\
426.72 & 117 & 163 & 1071 & -1.796 & -3.453 & -3.631 & 1.332 \\
\hline
\end{tabular}

was conducted. It is shown that after refreezing the further cooling of a well can be approximated by a constant (per unit of length) linear heat source. Hence, a modified Horner equation can be used for predicting the temperature of frozen formations for estimation of the formation temperature. A simple method to process field temperature data is presented. To demonstrate this approach, temperature shut-in time data for four depths from four wells in Alaska were successively used (Kutasov \& Eppelbaum 2018).

We did not have an access to the drilling journal of this borehole to estimate the time of thermal disturbance, $t_{c}$ (at a given depth), caused mainly by circulation of the drilling mud. For this reason, we consider thermal disturbance to

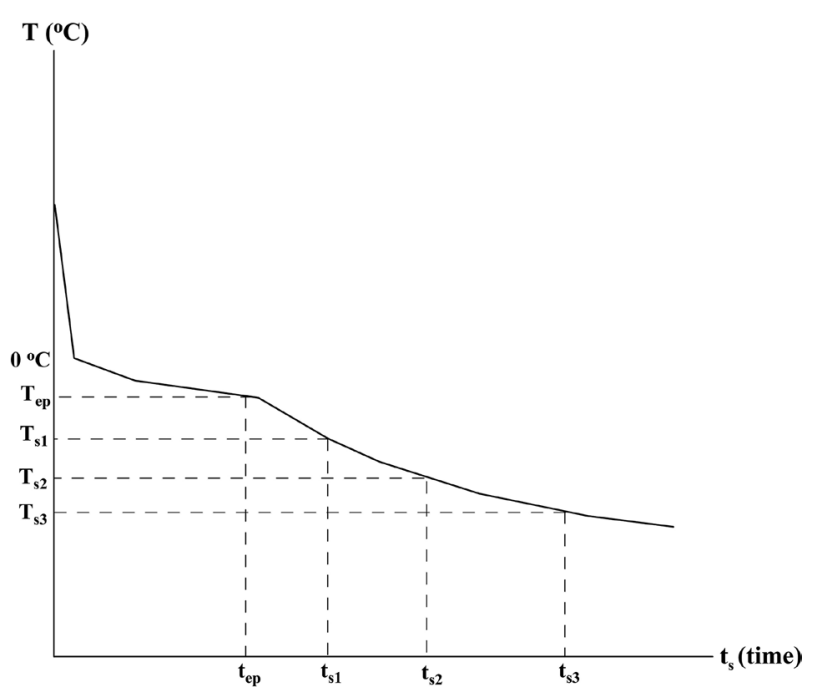

Fig. 3 Shut-in temperatures at a given depth shown as a schematic curve.

start at the moment of time when the bit reached a given depth and the end of thermal disturbance is the moment when the drilling operations are completed. Then

$$
t_{c}=t_{\text {tot }}\left(1-\frac{z}{H}\right)
$$

where $t_{\text {tot }}$ is the total drilling time, $H_{\mathrm{t}}$ is the vertical well depth and $z$ is the current depth. Now we can consider that the period of time $t^{*}{ }_{c}=t_{c}+t_{0}$ as a new "thermal disturbance" period $\left(t_{0}=t_{s 1}\right)$. Here $t_{s 1}$ is the shut-in time for the first temperature log (Fig. 4). Therefore, for logs 2 and 3 the modified Horner equations are 


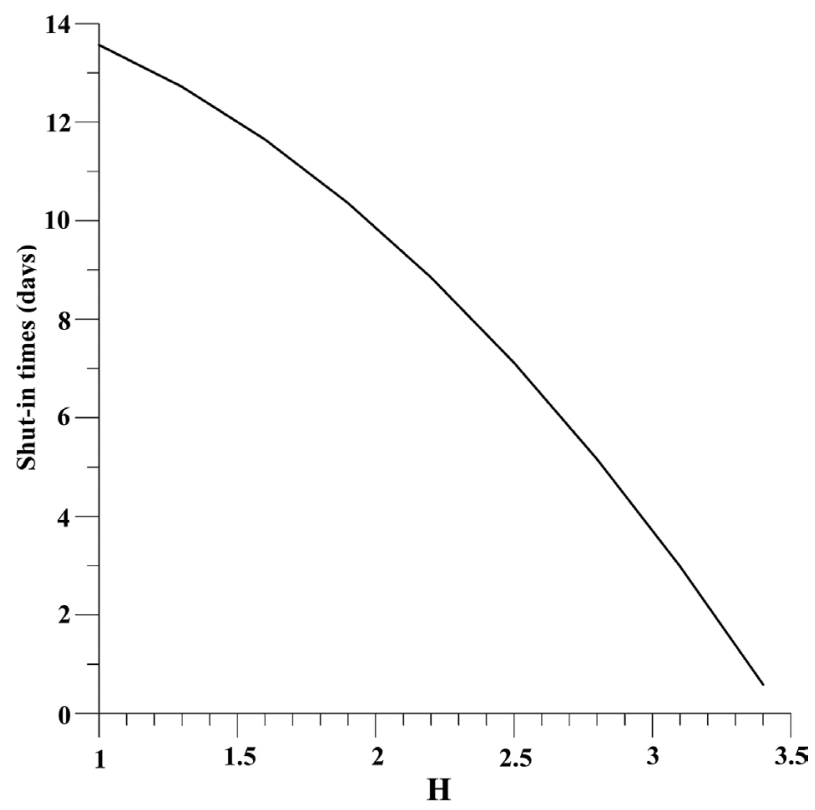

Fig. 4 The dimensionless radius of thawing versus shut-in time. Depth is $274.32 \mathrm{~m}$, the maximum dimensionless radius thawing 3.47 and the formation temperature $-6.19^{\circ} \mathrm{C}$.

$$
\begin{aligned}
& T_{s 3}=B \ln \left(1+\frac{t_{c}+t_{0}}{t_{s 3}-t_{0}}\right)+T_{f}, \\
& T_{s 2}=B \ln \left(1+\frac{t_{c}+t_{0}}{t_{s 2}-t_{0}}\right)+T_{f} .
\end{aligned}
$$

From Eqns. 21 and 22, we can estimate the parameter $B$ for a given depth and the formation temperature:

$$
B=\frac{T_{s 3}-T_{s 2}}{\ln \left(1+\frac{t_{c}+t_{0}}{t_{s 3}-t_{0}}\right)-\ln \left(1+\frac{t_{c}+t_{0}}{t_{s 2}-t_{0}}\right)} .
$$

The results of calculations after Eqns. 22 and 23 are presented in Table 4.

\section{The radius of thawing in the drilling period}

Results of calculations after Eqns. 1, 2, 6-9 are presented in Table 5 .

$$
t_{D}=\frac{t_{c} a_{f}}{r_{w}^{2}}
$$

where $t_{D}$ is the dimensionless drilling mud circulation time.
Table 5 The dimensionless radius of thawing, $I_{\alpha}=0.7285, I_{k a}=0.9780$.

\begin{tabular}{lccccc}
\hline$z(\mathrm{~m})$ & $t_{D}$ & $\theta$ & $I_{f}$ & $\Psi$ & $H$ \\
\hline 30.48 & 80.92 & 1.1380 & 1.327 & 0.8382 & 3.19 \\
45.72 & 79.24 & 1.1560 & 1.327 & 0.8417 & 3.16 \\
60.96 & 77.55 & 1.1290 & 1.327 & 0.8365 & 3.18 \\
91.44 & 74.18 & 1.1270 & 1.327 & 0.8361 & 3.15 \\
121.92 & 70.82 & 1.1640 & 1.327 & 0.8433 & 3.07 \\
152.40 & 67.45 & 1.0950 & 1.327 & 0.8297 & 3.13 \\
182.88 & 64.08 & 0.9510 & 1.327 & 0.7985 & 3.30 \\
213.36 & 60.72 & 0.8980 & 1.327 & 0.7860 & 3.35 \\
243.84 & 57.35 & 0.8460 & 1.327 & 0.7731 & 3.39 \\
274.32 & 53.98 & 0.7740 & 1.327 & 0.7541 & 3.47 \\
304.80 & 50.62 & 0.6980 & 1.327 & 0.7325 & 3.56 \\
335.28 & 47.25 & 0.6340 & 1.327 & 0.7128 & 3.64 \\
365.76 & 43.88 & 0.5730 & 1.327 & 0.6927 & 3.70 \\
396.24 & 40.51 & 0.5230 & 1.327 & 0.6751 & 3.75 \\
426.72 & 37.15 & 0.4540 & 1.327 & 0.6488 & 3.84
\end{tabular}

Table 6 The time of the complete freezeback.

\begin{tabular}{lccc}
\hline$z(\mathrm{~m})$ & $H$ & $T_{f}\left({ }^{\circ} \mathrm{C}\right)$ & $t_{c f}$ (days) \\
\hline 30.48 & 3.190 & -9.101 & 7.46 \\
45.72 & 3.160 & -9.248 & 7.19 \\
60.96 & 3.180 & -9.029 & 7.48 \\
91.44 & 3.150 & -9.016 & 7.33 \\
121.92 & 3.070 & -9.316 & 6.68 \\
152.40 & 3.130 & -8.763 & 7.45 \\
182.88 & 3.300 & -7.609 & 9.74 \\
213.36 & 3.350 & -7.182 & 10.71 \\
243.84 & 3.390 & -6.767 & 11.72 \\
274.32 & 3.470 & -6.190 & 13.57 \\
304.80 & 3.560 & -5.587 & 16.01 \\
335.28 & 3.640 & -5.069 & 18.66 \\
365.76 & 3.700 & -4.584 & 21.54 \\
396.24 & 3.750 & -4.186 & 24.46 \\
426.72 & 3.840 & -3.631 & 30.02 \\
\hline
\end{tabular}

It is interesting to note that the dimensionless radius of thawing varies in narrow limits (Table 5). This can be explained by a combination of two factors: (1) the radius of thawing increases with depth (due to temperature increase with depth); (2) the time of mud circulation reduces with depth and the radius of thawing reduces with depth. The time of complete freezeback was calculated after Eqn. 19 (Table 6).

\section{Conclusions}

Drilling intermediate and deep wells in permafrost areas usually includes a warm mud application with unknown dynamics of the formation thawing around the wells. A new method based on the phase change (Stefan problem) 
around a cylindrical source is proposed. This method allows for the estimation of the radius of thawing during drilling and shut-in periods. Determining formation temperature and estimating the time of complete freezeback are illustrated with an example of field case.

\section{Acknowledgements}

The authors would like to thank two anonymous reviewers, who thoroughly reviewed the manuscript. Their critical comments and valuable suggestions were helpful in preparing this article.

\section{Disclosure statement}

The authors declare that they have no conflicts of interest.

\section{References}

Carslow H.S. \& Jaeger J.C. 1959. Conduction of heat in solids. 2nd edn. Oxford: Oxford University Press.

Churchill S.W. \& Gupta J.P. 1977. Approximations for conduction with freezing or melting. International Journal of Heat and Mass Transfer 20, 1251-1253, http://dx.doi. org/10.1016/0017-9310(77)90134-X.

Clow G.D. 2014. Temperature data acquired from the DOI/ GTN-P Deep Borehole Array on the Arctic Slope of Alaska, 1973-2013. Earth System Science Data 6, 201-218, http:// dx.doi.org/10.5194/essd-6-201-2014.

Dobinski W. 2011. Permafrost. Earth-Science Reviews 108, 158-169, http://dx.doi.org/10.1016/j.earscirev.2011.06.007.

Edwardson M.L., Girner H.M., Parkinson H.R., Williams C.D. \& Matthews C.S. 1962. Calculation of formation temperature disturbances caused by mud circulation. Journal of Petroleum Technology 14(4), 416-426, http://dx.doi.org/ 10.2118/124-PA.

Eppelbaum L.V., Kutasov I.M. \& Pilchin A.N. 2014. Applied geothermics. Heidelberg: Springer.

Harlan R.L. 1973. Analysis of coupled heat-fluid transport in partially frozen soil. Water Resources Research 9, 1314-1323, http://dx.doi.org/10.1029/WR009i005p01314.

Hasan A.R. \& Kabir C.S. 1994. Aspects of wellbore heat transfer during two-phase flow. SPE Production $\theta$ Facilities 9, $211-216$, http://dx.doi.org/10.2118/22948-PA.

Hnatiuk J. \& Randall A.G. 1977. Determination of permafrost thickness in wells in northern Canada. Canadian Journal of Earth Sciences 14, 375-383, http://dx.doi.org/ 10.1139/e77-038.

Jaeger J.C. 1961. The effect of the drilling fluid on temperature measured in boreholes. Journal of Geophysical Research 66, 563-569.

Judge A.S., Taylor A.E., Burgess M. \& Allen V.S. 1981. Canadian geothermal data collection: northern wells 1978-80. Geothermal Series 12. Ottawa: Earth Physics Branch, Energy, Mines and Resources.
Kutasov I.M. 1987. Dimensionless temperature, cumulative heat flow and heat flow rate for a well with a constant bore-face temperature. Geothermics 16, 467-472, http://dx. doi.org/10.1016/0375-6505(87)90032-0.

Kutasov I.M. 1998. Melting around a cylindrical source with a constant wall temperature. In G.E. Tupholme $\delta$ A.S. Wood (eds.): Mathematics of heat transfer. Pp. 213-218. Oxford: Clarendon Press.

Kutasov I.M. 1999. Applied geothermics for petroleum engineers. Amsterdam: Elsevier.

Kutasov I.M. 2006. Radius of thawing around an injection well and time of complete freezeback. Journal of Geophysics and Engineering 3, 154-159, http://dx.doi.org/ 10.1088/1742-2132/3/2/006.

Kutasov I.M., Balobayev V.T. \& Demchenko R.Y. 1977. Metod "shivaniya" reshenii pri opredelenii ploskoi I zilindricheskoi granitzy razdela faz $\mathrm{f}$ zadache Stefana. (Method of "joining" of solutions in the determination of a plane and a cylindrical phase interface in the Stefan problem.) Engineering-Physical Journal (Inzhinerno-Geofizicheskii Zhurnal) 33, 148-152.

Kutasov I.M. \& Eppelbaum L.V. 2003. Prediction of formation temperatures in permafrost regions from temperature logs in deep wells-field cases. Permafrost and Periglacial Processes 14, 247-258.

Kutasov I.M. \& Eppelbaum L.V. 2017a. Time of refreezing of surrounding the wellbore thawed formations. International Journal of Thermal Science 122, 133-140, http://dx.doi. org/10.1016/j.ijthermalsci.2017.07.031.

Kutasov I.M. \& Eppelbaum L.V. 2017b. Corrigendum to "Time of refreezing of surrounding the wellbore thawed formations." International Journal of Thermal Science 124, 548.

Kutasov I.M. \& Eppelbaum L.V. 2018. Utilization of the Horner plot for determining the temperature of frozen formations-a novel approach. Geothermics 71, 259-263, http://dx.doi.org/10.1016/j.geothermics.2017.10.005.

Kutasov I.M., Lubimova E.A. \& Firsov F.V. 1966. Skorost' vosstanovleniya temperaturnogo polya $\mathrm{v}$ skvazhinah Kol'skogo poluostrova. (Rate of recovery of the temperature field in wells in Kola Peninsula.) In: Problemy glubinnogo teplovogo potoka. (Problems of heat flux at depth.) Pp. 74-87. Moscow: Nauka.

Lachenbruch A.H. \& Brewer M.C. 1959. Dissipation of the temperature effect of drilling a well in Arctic Alaska. U.S. Geological Survey Bulletin 1083-C, 74-109.

Lin S. 1971. One-dimensional freezing or melting processes in a body with variable cross-sectional area. International Journal of Heat and Mass Transfer 14, 153-156, http://dx.doi. org/10.1016/0017-9310(71)90146-3.

Lunardini V.J. 1988. Heat conduction with freezing or thawing. CRREL Monograph 88-1. Hanover, NH: US Army Corps of Engineers.

Melnikov P.I., Balobayev V.T., Kutasov I.M. \& Devyatkin V.N. 1973. Geothermal studies in central Yakutia. International Geology Review 16, 565-568.

Ramey H.J.J. 1962. Wellbore heat transmission. Journal of Petrology Technology 14(4), 427-435. 
Raymond L.R. 1969. Temperature distribution in a circulating drilling fluid. Journal of Petroleum Technology 21(3), 333-341, http://dx.doi.org/10.2118/2320-PA.

Romanovsky V.E., Gruber S., Instanes A., Jin H., Marchenko S.S., Smith S.L., Trombotto D. \& Walter K.M. 2007. Frozen ground. In: UNEP global outlook for ice $\theta$ snow. Pp. 181-200. Nairobi: Division of Early Warning and Assessment, United Nations Environment Programme.

Shiu K.C. \& Beggs H.D. 1980. Predicting temperatures in flowing oil wells. Journal of Energy Resources Technology-Transactions of the ASME 102(1), 2-11, http://dx.doi. org/10.1115/1.3227845.

Sparrow S.W., Ramadhyani S. \& Patankar S.V. 1978. Effect of subcooling on cylindrical melting. Journal of Heat Transfer 100, 395-402, http://dx.doi.org/10.1115/1. 3450821 .

Taylor A.E. 1978. Temperatures and heat flow in a system of cylindrical symmetry including a phase boundary. Geothermal Series 7. Ottawa: Earth Physics Branch, Energy, Mines and Resources.
Taylor A.E., Burgess M., Judge A.S. \& Allen V.S. 1982. Canadian geothermal data collection: northern wells 1981. Geothermal Series 13. Ottawa: Earth Physics Branch, Energy, Mines and Resources.

Tien L.C. \& Churchill S.W. 1965. Freezing front motion and heat transfer outside an infinite isothermal cylinder. A.I.Ch.E. Journal 11(5), 790-793, http://dx.doi.org/ 10.1002/aic.690110509.

Tsytovich N.A. 1975. The mechanics of frozen ground. Washington, DC: Scripta Book Co.

USGS 1998. Boreholes locations and permafrost depths. AK: U.S. Geological Survey. Accessed on the internet at https:// nsidc.org/data/GGD223 on 5 April 2019.

Wang X., Wang Z., Deng X., Sun B., Zhao Y. \& Fu W. 2017. Coupled thermal model of wellbore and permafrost in Arctic regions. Applied Thermal Engineering 123, 291-299, http://dx.doi.org/10.1016/j.applthermaleng.2017.05.186.

Wu Y.S. \& Pruess K. 1990. An analytical solution for wellbore heat transmission in layered formations. SPE Reservoir Engineering 5, 531-538, http://dx.doi.org/10.2118/17497-PA. 